\section{Medicamentos genéricos no Brasil: panorama histórico e legislação}

\author{
Lorena Ulhôa Araújo, ${ }^{1}$ Kemile Toledo \\ de Albuquerque, ${ }^{1}$ Kelly Cristina Kato, ${ }^{1}$ \\ Gleiciely Santos Silveira, ${ }^{1}$ Náira \\ Rezende Maciel, ${ }^{1}$ Pollyanna Álvaro \\ Spósito, ${ }^{1}$ Neila Márcia Silva Barcellos, ${ }^{1}$ \\ Jacqueline de Souza, ${ }^{1}$ Márcia Bueno ${ }^{2}$ \\ e Sílvia Storpirtis ${ }^{3}$
}

Como citar: Araújo LU, Albuquerque KT, Kato KC, Silveira GS, Maciel NR, Spósito PA, et al. Medicamentos genéricos no Brasil: panorama histórico e legislação. Rev Panam Salud Publica. 2010; 28(6):480-92.

\section{SINOPSE}

A política de medicamentos genéricos foi implantada no Brasil em 1999 com o objetivo de estimular a concorrência comercial, melhorar a qualidade dos medicamentos e facilitar o acesso da população ao tratamento medicamentoso. $O$ processo de implementação dessa política permitiu a introdução e a discussão de conceitos nunca antes utilizados para o registro de medicamentos no Brasil: biodisponibilidade, bioequivalência, equivalência farmacêutica, medicamentos genéricos, sistema de classificação biofarmacêutica e bioisenção. Este artigo apresenta a definição desses conceitos no contexto das leis brasileiras e oferece uma descrição histórica e cronológica da implementação da política de genéricos no Brasil, listando ainda as resoluções que atualmente estão em vigor. Os resultados contribuem para a compreensão do processo e facilitam a busca e a identificação de ensaios necessários para satisfazer os critérios legais.

Palavras-chave: Equivalência farmacêutica; disponibilidade biológica; medicamentos genéricos; legislação; Brasil.

\footnotetext{
Universidade Federal de Ouro Preto, Escola de Farmácia, Departamento de Farmácia, Ouro Preto, MG, Brasil. Correspondência: Neila Márcia Silva Barcellos, neila@ef.ufop.br

2 Libbs Farmacêutica Ltda., Assuntos Regulatórios e Farmacovigilância, Embu das Artes, São Paulo, SP, Brasil.

3 Universidade de São Paulo, Faculdade de Ciências Farmacêuticas, Departamento de Farmácia, São Paulo, SP, Brasil.
}

No Brasil, o reconhecimento de que a utilização das denominações genéricas constitui um dos mecanismos de regulação de preços dos medicamentos levou, em 1993, à adoção dos medicamentos genéricos como política do setor de saúde e de economia do governo brasileiro (1). A partir de então, tornou-se obrigatório o uso da Denominação Comum Brasileira (DCB) para todos os medicamentos e da Nomenclatura Comum do Mercosul (NCM) no caso da importação de produtos e insumos farmacêuticos. A partir de 1999, a política foi efetivamente implantada, com a entrada em vigor da Lei dos Genéricos (2).

A regulamentação da Lei dos Genéricos por meio de uma Resolução da Diretoria Colegiada da Agência Nacional de Vigilância Sanitária (ANVISA), ainda em 1999, possibilitou, naquele momento, a introdução de conceitos nunca antes empregados para o registro de um medicamento no Brasil $(2,3)$, como por exemplo a equivalência farmacêutica (comprovada por ensaios in vitro) e a bioequivalência (comprovada por ensaios in vivo). Desse modo, a Lei dos Genéricos estabeleceu um novo padrão para o desenvolvimento e o registro de medicamentos no país.

O amplo intervalo entre a primeira legislação sobre a obrigatoriedade da utilização da denominação genérica e a efetiva implementação da política de medicamentos genéricos no Brasil (de 1993 a 1999) deveu-se, em parte, à existência, no mercado brasileiro, de inúmeros medicamentos similares ao medicamento de referência, comercializados por diferentes laboratórios. Essas empresas, buscando a manutenção de seus produtos no mercado, só passariam a investir no desenvolvimento de produtos genéricos após o vencimento de seus registros, retardando assim a efetiva implantação dos genéricos.

Cabe ressaltar que, no período compreendido entre os anos de 1976 e 1999, a legislação brasileira permitia às empresas fabricantes definirem elas próprias qual seria o medicamento de referência para o registro de seus similares. Entretanto, não havia exigência de comprovação da equivalência terapêutica do similar em relação ao medicamento considerado como referência (4). Era também permitido o registro de formas farmacêuticas e dosagens diferentes em relação ao suposto medicamento de referência, havendo, ainda, casos de formulações distintas, o que deu origem ao registro de muitas alternativas farmacêuticas (medicamentos que diferem do medicamento de referência em relação a um ou mais dos seguintes itens: base, sal ou éster do fármaco, dosagem, forma farmacêutica). Em consequência, até a publicação de uma lei que regulou os direitos e as obrigações relativos à propriedade industrial (5), foram registradas inúmeras especialidades contendo o mesmo fármaco, comercializadas com 
diversos nomes comerciais por diferentes laboratórios (5-7).

Além disso, após a publicação da regulamentação técnica para o registro de medicamentos genéricos, tornou-se inconcebível a existência de critérios distintos para o registro de medicamentos similares no país. Isso acelerou o processo de criação da regulamentação técnica que exige comprovação da equivalência terapêutica entre o medicamento similar e o medicamento de referência indicado pela ANVISA, tanto para as novas solicitações de registro (RDC 133/2003), como para os similares já registrados (RDC 134/2003) $(8,9)$. De fato, a experiência adquirida com o registro dos medicamentos genéricos tornou viável a publicação da RDC 134/2003, segundo a qual os fabricantes de similares são obrigados a cumprir os requisitos de equivalência farmacêutica e de biodisponibilidade relativa, de acordo com um cronograma elaborado considerando-se o conceito de risco sanitário (cronograma de adequação) (9).

Atualmente, existem dois tipos de similares no mercado brasileiro de medicamentos: aqueles cujos registros já estão de acordo com a nova legislação e aqueles que ainda estão no processo de adequação, que ocorre por ocasião da renovação do registro sanitário. Segundo o referido cronograma, estima-se que até 2014 todos os fabricantes de medicamentos similares já terão atendido aos critérios de adequação (7).

Após esse período de adequação, o similar que passar no teste de biodisponibilidade relativa poderá ser considerado bioequivalente ao respectivo medicamento de referência. Entretanto, não será intercambiável, por questões legais, a menos que a legislação seja alterada futuramente. Segundo a regulamentação técnica atual, a intercambialidade é prevista apenas para o genérico bioequivalente ao medicamento de referência, exigindo-se, ainda, sua comercialização com o nome genérico de acordo com a DCB ou, na sua falta, com a denominação comum internacional (DCI) (10).

Também é importante destacar que houve um contexto social e político favorável às mudanças causadas pelas regulamentações técnicas já mencionadas. Os casos de falsificação de medicamentos no mercado nacional, notadamente em 1998 e 1999, geraram um clamor pela segurança e qualidade de produtos relacionados à saúde. Nesse cenário, foi criada a ANVISA, com a missão de proteger e promover a saúde da população (7), sendo que uma de suas primeiras ações foi a publicação da Lei dos Genéricos, como parte da Política Nacional de Medicamentos, voltada ao estímulo da concorrência e da variedade de oferta de medicamentos no mercado, à melhoria da qualidade de todos os medicamentos, à redução dos preços e, especialmente, à facilitação do acesso aos tratamentos terapêuticos por parte da população $(2,7)$. No Brasil, como na Europa e nos Estados Unidos, a política de incentivo ao registro e ao uso de genéricos tem-se mostrado eficaz na regulação do preço dos medicamentos, favorecendo o direito de escolha do consumidor. Ao mesmo tempo, fornece uma alternativa aos profissionais de não prescreverem apenas pelos nomes comerciais impostos por multinacionais farmacêuticas $(1,11)$. No entanto, o acesso aos medicamentos pela população brasileira ainda é um grande desafio. Os laboratórios públicos têm sua produção de medicamentos direcionada à atenção básica de enfermidades desatendidas ou às doenças tropicais $(12,13)$.

Pelo exposto, após 10 anos do início da implantação da política de medicamentos genéricos no Brasil, este artigo tem por objetivo contribuir para a compreensão dos conceitos de medicamento genérico, equivalência farmacêutica, bioequivalência ou biodisponibilidade relativa, classificação biofarmacêutica e bioisenção, de acordo com as legislações vigentes. Além disso, visa ao relato histórico e cronológico da implantação da política de genéricos, subsidiado pelo conteúdo das legislações pertinentes e de suas atualizações.

\section{LEVANTAMENTO DAS INFORMAÇÕES}

Foi realizada uma revisão da legislação brasileira relativa à política de medicamentos genéricos no Brasil, desde a sua implantação em 1999. Inicialmente, foi pesquisado o site da ANVISA (http://www.anvisa. gov.br/e-legis). Adicionalmente, realizou-se uma busca de artigos científicos que permitissem o embasamento para apresentação e discussão das legislações citadas. Para tanto, foram examinadas as bases de dados bibliográficos PubMed (www.ncbi.nlm.nih. gov) e SciELO (www.scielo.org) para o período de 1999 a 2010, utilizando os seguintes termos de busca: equivalência farmacêutica, bioequivalência, biodisponibilidade relativa, legislação brasileira, medicamentos genéricos e regulamentação ANVISA. Foram ainda pesquisadas publicações relativas ao setor saúde disponíveis na Biblioteca Virtual em Saúde (www.bvs. $\mathrm{br} / \mathrm{php} /$ index.php) e livros texto sobre saúde ocupacional, políticas de saúde e correlatos.

\section{CONCEITOS}

A ANVISA é uma agência reguladora caracterizada pela independência administrativa, estabilidade de seus dirigentes durante o período de mandato e autonomia financeira. As propostas de atos normativos da ANVISA podem ser submetidas a consulta pública, a critério da diretoria colegiada, e podem transformar-se em resolução da diretoria colegiada (RDC), que tem força de lei. As resoluções específicas (REs) são atos normativos publicados após discussão e aprovação por uma gerência específica da ANVISA.

\section{Medicamento genérico}

A Lei dos Genéricos (lei 9787 de 10 de fevereiro de 1999) estabelece que o genérico é um medicamento similar e intercambiável com um produto de referência ou inovador. O medicamento inovador é o primeiro produto registrado e detentor da patente, sendo normalmente indicado como medicamento referência, exceto em casos onde não existe disponibilidade no comércio local. Nesse caso, a ANVISA indica como re- 
ferência outro produto com eficácia garantida. O genérico é normalmente produzido após expiração ou renúncia da proteção patentária ou de outros direitos de exclusividade, devendo ter sua eficácia, segurança e qualidade comprovadas e sendo designado pela DCB ou, na sua ausência, pela DCI. Vale ressaltar a possibilidade de produção de genéricos ainda durante a proteção patentária por meio do mecanismo chamado de licença compulsória, que permite garantir o fornecimento ao mercado de produtos essenciais em casos extremos, nos quais as empresas detentoras das patentes não consigam suprir o mercado, não fabriquem o produto ou se neguem a licenciá-lo (14).

Medicamentos genéricos devem apresentar o mesmo fármaco, na mesma quantidade e forma farmacêutica do medicamento eleito como referência, ou seja, devem ser caracterizados como um equivalente farmacêutico do medicamento de referência, devendo também cumprir os requisitos dos estudos de bioequivalência (2). O medicamento de referência é, geralmente, o inovador cuja biodisponibilidade foi determinada durante o desenvolvimento do produto e que teve sua eficácia e segurança comprovadas por meio de ensaios clínicos antes da obtenção do registro para comercialização (15).

Com relação à prescrição e à dispensação, no âmbito do Sistema Único de Saúde (SUS) o profissional prescritor deverá adotar obrigatoriamente a DCB ou, na sua falta, a DCI. Nos serviços privados de saúde, a prescrição pode ser realizada sob o nome genérico ou comercial, e o profissional prescritor poderá ressaltar, quando necessário, as restrições de intercambialidade. A RDC 135, de 29 de maio de 2003, explicita que a restrição à intercambialidade deverá ser efetuada para cada item prescrito, devendo ser escrita de próprio punho, sendo proibido o uso de carimbos, etiquetas ou qualquer outra forma automática de manifestação. $\mathrm{O}$ farmacêutico pode, a seu critério ou a pedido do paciente, substituir o medicamento prescrito pelo genérico correspondente, desde que o prescritor não tenha restringido a intercambialidade. Nesses casos, deve indicar a substituição na prescrição, colocar seu carimbo, com nome, número de inscrição no Conselho Regional de Farmácia (CRF), datar e assinar. Como em qualquer dispensação de medicamentos, o farmacêutico deve orientar o paciente para o consumo racional do medicamento (16).

\section{Equivalência farmacêutica}

Segundo a ANVISA, equivalentes farmacêuticos são medicamentos que contém o mesmo fármaco, isto é, mesmo sal ou éster da mesma molécula terapeuticamente ativa, na mesma quantidade e forma farmacêutica, podendo ou não conter excipientes idênticos. Os equivalentes farmacêuticos devem cumprir as especificações atualizadas da Farmacopéia Brasileira e, na ausência dessas, devem cumprir as especificações de outros códigos autorizados pela legislação vigente ou, ainda, outros padrões aplicáveis de qualidade $(17,18)$.
A RE 310, de $1^{\circ}$ de setembro de 2004, que publicou o Guia para realização do estudo e elaboração do relatório de equivalência farmacêutica e perfil de dissolução, determina que os testes relativos à identificação, à forma farmacêutica específica e à quantificação do teor devem, preferencialmente, ser realizados nos produtos teste e referência com até 6 meses de fabricação. Ainda nessa resolução são estabelecidos critérios para o estudo de equivalência farmacêutica para três grupos de medicamentos: 1) isentos do estudo de bioequivalência; 2) aqueles em que o estudo de equivalência farmacêutica substitui o estudo de bioequivalência e 3) aqueles que serão submetidos ao estudo de bioequivalência (17).

\section{Bioequivalência ou biodisponibilidade relativa}

Como citado anteriormente, a adequação dos medicamentos similares no Brasil deverá ocorrer até 2014. Por essa razão, a ANVISA adotou o termo biodisponibilidade relativa, para diferenciar os similares já existentes dos genéricos intercambiáveis, para os quais o termo bioequivalência está consagrado e internacionalmente aceito (5).

De acordo com a ANVISA, a biodisponibilidade relativa é o quociente entre a biodisponibilidade de um medicamento teste e a de um medicamento referência, utilizando os valores da área total sob a curva (ASC) da concentração plasmática em função do tempo na comparação. Uma biodisponibilidade relativa igual a 1, ou seja, uma biodisponibilidade de $100 \%$, implica que os dois medicamentos foram absorvidos na mesma extensão, mas não indica a sua completa absorção sistêmica. Já a biodisponibilidade absoluta de um fármaco administrado por via oral pode ser calculada por comparação entre a ASC após a administração oral e a ASC obtida após a administração do medicamento, se possível, pela via intravascular (19).

A determinação da bioequivalência consiste na demonstração de equivalência farmacêutica entre produtos apresentados sob a mesma forma farmacêutica, contendo idêntica composição qualitativa e quantitativa de princípios ativos e que tenham comparável biodisponibilidade quando estudados sob um mesmo desenho experimental (2). Os estudos de bioequivalência são necessários, por exemplo, nas seguintes situações: uma proposta de forma farmacêutica diferente daquela usada nos testes clínicos; alterações significativas na produção da formulação; e o teste de nova formulação genérica comparativamente a um produto inovador (20).

Cabe ressaltar que a bioequivalência pode ser considerada como um caso particular de biodisponibilidade relativa, uma vez que corresponde a um dos critérios de registro de medicamentos genéricos, que também devem cumprir o requisito de equivalência farmacêutica e atender os critérios das Boas Práticas de Fabricação e Controle de Qualidade (BPFC) para produtos farmacêuticos como forma de garantir sua equivalência terapêutica e, consequentemente, a intercambialidade com o medicamento de referência (5). As BPFC, 
normatizadas pela ANVISA, seguem critérios mundialmente aceitos de boas práticas (Good Manufacture Pratices e Good Laboratory Pratices).

No contexto da biodisponibilidade e da bioequivalência, as formas farmacêuticas sólidas merecem especial atenção, uma vez que sua dissolução pode ser afetada significativamente pelas características inerentes ao próprio fármaco, bem como pela presença de excipientes que favorecem ou dificultam a dissolução, além das técnicas de fabricação empregadas. As formas farmacêuticas sólidas de uso oral, de liberação imediata ou modificada, são as que, potencialmente, podem apresentar problemas de biodisponibilidade e bioequivalência (21). Assim, a comparação de perfis de dissolução é útil nos casos em que se deseja conhecer o comportamento de dois produtos antes de submetêlos a ensaios de biodisponibilidade relativa ou de bioequivalência, bem como para isentar as dosagens menores desses estudos e para verificar os casos de alterações pós-registro (22).

De acordo com a RE 1 170, de 19 de abril de 2006, o estudo de bioequivalência deve ter três etapas: clínica, analítica e estatística (23). Na etapa clínica, são realizadas a seleção dos voluntários, a administração das preparações farmacêuticas em estudo e a coleta das amostras de sangue, as quais serão congeladas até o momento da quantificação. O estudo convencional é do tipo aberto, aleatório e cruzado. O número de voluntários deverá ser estatisticamente significativo, não sendo permitida a utilização de número inferior a 12 participantes. Na falta de dados relativos ao coeficiente de variação do fármaco, pode-se optar por utilizar um número mínimo de 24 voluntários. A ANVISA recomenda que os voluntários tenham idade superior a 18 anos e peso corporal de mais ou menos $15 \%$ do peso considerado normal para homens e mulheres, levando-se em consideração altura e estrutura física. Para tal é calculado o índice de massa corporal (IMC), determinado pela divisão da massa do indivíduo pelo quadrado de sua altura, onde a massa é expressa em quilogramas e a altura em metros. Valores de IMC dentro da faixa de 18,5 a 24,9 são considerados normais e saudáveis.

Devem-se evitar indivíduos fumantes e com histórico de abuso de álcool ou drogas. $\mathrm{O}$ intervalo entre os períodos do estudo deve ser de, no mínimo, 7 meiasvidas de eliminação do fármaco e/ou metabólito $\left(t_{1 / 2 \beta}\right)$. O cronograma de coleta das amostras deverá garantir a adequada caracterização do perfil plasmático do fármaco ou metabólito (concentração versus tempo), contemplando um tempo igual ou superior a 3 até 5 vezes o valor de $t_{1 / 2 \beta}$ dos mesmos. No caso de fármacos que apresentam $t_{1 / 2 \beta}$ superior a 24 horas pode-se utilizar um cronograma de coletas alternativo, de no mínimo 72 horas $(22,23)$.

A etapa analítica é aquela em que o fármaco é quantificado nas amostras biológicas. Durante o planejamento da etapa analítica devem ser estabelecidos o analito a ser quantificado, a matriz biológica utilizada e o método analítico adequado, que deve ser específico para cada analito, exato e relativamente simples, de modo a minimizar os erros, sendo que o método deve estar devida- mente validado antes da realização do estudo (21). A validação consiste na avaliação de parâmetros que permitam atestar que o método pode ser utilizado para o fim a que se destina, possibilitando a obtenção de resultados precisos, exatos e isentos de interferentes, dentro de uma margem de erro estabelecida (24).

A etapa estatística inicia-se com o cálculo do número adequado de voluntários para o fármaco em questão e finaliza com o tratamento a que serão submetidos os dados gerados na etapa analítica (25). Não é aceita a exclusão de mais do que 5\% dos voluntários do estudo ou a ausência de mais de $10 \%$ dos valores das concentrações sanguíneas do fármaco provenientes da administração de cada medicamento por voluntário. Quanto ao tratamento dos dados, os estudos de bioequivalência utilizam os parâmetros farmacocinéticos que derivam diretamente das curvas de concentração plasmática do fármaco em função dos tempos de coletas da matriz biológica empregada no estudo. São eles: ASC, que fornece uma estimativa direta sobre a quantidade de fármaco absorvida, concentração plasmática máxima atingida após a administração da dose do medicamento $\left(C_{\max }\right)$ e o tempo necessário para alcançar $\mathrm{C}_{\max }\left(\mathrm{T}_{\max }\right)(21)$.

Para que os dois medicamentos sejam considerados bioequivalentes, não deve haver diferenças estatisticamente significativas entre os parâmetros ASC e $\mathrm{C}_{\max }$ para os medicamentos comparados, ou seja, diferenças em relação a extensão e velocidade de absorção. Para o cálculo estatístico é utilizada a análise de variância (ANOVA), que visa fundamentalmente à verificação de diferenças significativas entre as médias e à avaliação da influência dos fatores de variabilidade sobre alguma variável dependente, permitindo que vários grupos sejam comparados ao mesmo tempo. A ANOVA deve ser realizada na avaliação dos parâmetros farmacocinéticos $\mathrm{ASC}_{0-\mathrm{t}} \mathrm{e}_{\text {max }^{\prime}}$ calculando-se também os intervalos de confiança de $90 \%$ (IC90\%) para as razões dos parâmetros $\mathrm{ASC}_{0 \text {-t (teste) }} / \mathrm{ASC}_{0 \text {-t (referência) }} \mathrm{e}$ $C_{\max (\text { teste) }} / C_{\max \text { (referência) }}$. Ambos os IC $90 \%$ devem estar entre $80 \%$ e $125 \%$ para que o medicamento teste seja considerado bioequivalente ao medicamento de referência. Limites diferentes para $C_{\text {máx }}$ poderão ser aceitos mediante justificativa científica incluída no protocolo do estudo de bioequivalência $(20,21)$.

\section{Sistema de Classificação Biofarmacêutica}

O Sistema de Classificação Biofarmacêutica (SCB) foi proposto por Amidon e colaboradores (26) como forma de agrupar os fármacos com base em suas características de solubilidade, permeabilidade e dissolução a partir da forma farmacêutica $(25,27)$. Na legislação brasileira sobre medicamentos, a ANVISA citou o SCB na RE 901, de 29 de maio de 2003, que contém em seu anexo o Guia para ensaios de dissolução para formas farmacêuticas sólidas orais de liberação imediata (FFSOLI) (28). No entanto, após a revogação dessa RE, o SCB não foi citado novamente, uma vez que ainda não se dispõe de regulamentação técnica pertinente a esse tema no Brasil. 
Os fármacos de alta solubilidade são aqueles que, em sua maior dosagem, administrados de uma única vez, se dissolvem em meio aquoso, com variação de $\mathrm{pH}$ de 1 a 6,8 (o que corresponde ao $\mathrm{pH}$ fisiológico encontrado no trato gastrintestinal), em um volume de $250 \mathrm{~mL}$ ou menos e temperatura de $37^{\circ} \mathrm{C}$. Fármacos de alta permeabilidade são aqueles que apresentam uma absorção intestinal superior a $80 \%$ ou biodisponibilidade igual ou superior a $90 \%$ (28).

Essas características podem facilitar o desenvolvimento de uma forma farmacêutica e o processo de aprovação de candidatos a fármaco. Para fármacos da classe I (alta solubilidade e alta permeabilidade), agências reguladoras como a Food and Drug Administration (FDA), nos Estados Unidos, consideram que formas sólidas de liberação imediata que contenham esses fármacos podem ser isentas do estudo de bioequivalência, desde que apresentem dissolução rápida. Os fármacos da classe I têm como passo limitante da velocidade de absorção apenas o esvaziamento gástrico, caso sua dissolução a partir da forma farmacêutica seja rápida. Já os fármacos da classe II (baixa solubilidade e alta permeabilidade) têm como passo limitante a dissolução; a absorção desses fármacos é geralmente menor do que os da classe I. Para os fármacos da classe III (alta solubilidade e baixa permeabilidade), a permeabilidade é o passo que controla a velocidade da absorção. Os fármacos da classe IV (baixas solubilidade e permeabilidade) apresentam problemas para a efetiva liberação oral (29).

Esse sistema, além de ser uma ferramenta muito útil para o desenvolvimento de especificações de dissolução in vitro para formas farmacêuticas, também pode fornecer as bases para prever quando uma correlação in vitro/in vivo (CIVIV) pode ser obtida com sucesso. O sistema também é de extremo valor para isentar um medicamento dos estudos de bioequivalência. A CIVIV é um modelo matemático que descreve a relação entre uma propriedade ou característica físicoquímica in vitro do medicamento, usualmente a velocidade ou a extensão da dissolução, e uma resposta relevante in vivo, como por exemplo, a concentração do fármaco no plasma $\left(\mathrm{C}_{\max }\right)$ ou a quantidade do fármaco absorvida (30-32).

\section{Bioisenção}

A bioisenção pode ser definida como a não exigência de um estudo de biodisponibilidade relativa ou de bioequivalência in vivo para o registro de um medicamento pela autoridade sanitária, quando um ensaio in vitro adequado pode substituir o estudo in vivo. Tal definição deu origem ao conceito da bioequivalência in vitro, que significa que é possível, em alguns casos, comprovar a bioequivalência por meio de ensaios in vitro. Isso se justifica plenamente em termos éticos pela redução dos ensaios para medicamentos empregando seres humanos (33).

Casos de bioisenção são previstos, por exemplo, para medicamentos apresentados sob determinadas formas farmacêuticas ou para fármacos da classe I do
SCB, como citado anteriormente. Segundo a RE 897, de 29 maio de 2003, os estudos de bioequivalência são dispensados para alguns produtos farmacêuticos. Nesses casos, a intercambialidade com o medicamento de referência é garantida pelo cumprimento da equivalência farmacêutica e das $\operatorname{BPFC}(25,27)$.

Nas soluções aquosas injetáveis administradas por via intravascular, o fármaco já está dissolvido e toda a dose é administrada diretamente na circulação, o que implica $100 \%$ de biodisponibilidade. Para um genérico desse tipo, a comprovação da equivalência farmacêutica e das BPFC é suficiente para garantir a intercambialidade com o medicamento de referência. Outro exemplo de isenção corresponde a determinadas soluções aquosas de administração oral, que também apresentam o fármaco já dissolvido e em condições de ser absorvido pelo organismo. Para tais medicamentos, a experiência internacional demonstrou que não é necessário requerer a comprovação da bioequivalência do genérico em relação ao de referência para fins de registro, uma vez que a bioinequivalência é altamente improvável, desde que a formulação do genérico não contenha qualquer substância que possa alterar a absorção do fármaco em relação à formulação do medicamento de referência $(21,33)$.

Na RE 897 de 29 maio de 2003 são apresentados os tipos de medicamentos que são dispensados dos estudos de bioequivalência. Todos esses medicamentos devem conter o mesmo fármaco, na mesma concentração em relação ao medicamento de referência e excipientes de mesma função, em concentrações compatíveis. No caso de medicamentos isentos de estudos de bioequivalência, a equivalência farmacêutica passa a ser o principal requisito que sustenta a intercambialidade $(21,33)$.

\section{EVOLUÇÃO HISTÓRICA DA LEGISLAÇÃO}

A lei 9 787, Lei dos Genéricos, estabeleceu as bases legais para a instituição do medicamento genérico no Brasil, visando a assegurar a sua qualidade, segurança e eficácia, garantindo assim sua intercambialidade com o produto de referência. Nessa legislação são apresentados os conceitos de denominação comum brasileira (DCB), denominação comum internacional (DCI), biodisponibilidade, bioequivalência, medicamento similar, genérico e de referência e produto farmacêutico intercambiável. A partir dela foram adotadas resoluções visando ao detalhamento técnico, o que correspondeu a um processo importante para a evolução e a consolidação da regulamentação sobre medicamentos genéricos no País (9). O anexo 1 relaciona as legislações referentes aos medicamentos genéricos publicadas pela ANVISA no período de 1999 a 2007, em ordem cronológica, de forma a permitir a visualização das resoluções revogadas e das que estão em vigor.

A primeira resolução publicada sobre o tema foi a RDC 391, de 9 de agosto de 1999, que aprovou o Regulamento técnico para medicamentos genéricos. Esse regulamento apresenta critérios e condições para o registro e o controle de qualidade desses medicamentos, 
para provas de biodisponibilidade de medicamentos em geral, provas de bioequivalência de medicamentos genéricos, bem como para a prescrição e a dispensação dos mesmos. Também são apresentados os mesmos conceitos da Lei dos Genéricos e acrescentados os conceitos de equivalente farmacêutico, alternativa farmacêutica, medicamento bioequivalente e inovador. Cerca de 1 ano e meio após sua publicação, a RE 391 foi revisada, sendo revogada pela RDC 10, de 2 de janeiro de $2001(3,15)$.

A RDC 10 manteve o mesmo formato da RDC 391, porém com maior detalhamento. Com relação aos conceitos, foi suprimido o de alternativa farmacêutica e inserido o de equivalência terapêutica. Foram adicionados diversos itens: 1) critérios para registro e controle de qualidade dos genéricos; 2) registro dos importados; 3) autorização para redução de lotes pilotos para medicamentos com alto valor agregado; 4) considerações para fármacos que apresentam quiralidade e polimorfismo; 5) guias para modelo de relatórios técnicos dos estudos de equivalência farmacêutica, biodisponibilidade e bioequivalência; 6) três novos anexos, os quais abordam: situações nas quais um novo estudo para comprovação de bioequivalência poderia ser exigido, medicamentos não aceitos para registro como genéricos e o Guia para estudos de CIVIV. Quanto às provas de bioequivalência de medicamentos, alterou-se o intervalo mínimo entre as duas fases da etapa clínica (administração dos produtos teste e referência) de 5 para 7 meias-vidas de eliminação. Quanto à etapa analítica, os valores de concentração plasmática do fármaco abaixo do limite de quantificação passaram a ser considerados iguais à zero, para efeito de cálculo. Já na etapa estatística, recomendouse a adoção do IC de 95\% (IC95\%) para fármacos de baixo índice terapêutico e explicitação do programa estatístico utilizado (15).

Em 19 de março de 2002, foi publicada a RDC 84, que revogou a RDC 10. A RDC 10 passou a apresentar os testes separadamente sob a forma de RE, permitindo uma visão mais detalhada e individualizada de cada etapa (34). A seguir a legislação sobre cada tema será descrita, em ordem cronológica, com destaque para os seus principais aspectos, as alterações ocorridas e as legislações atualmente em vigor.

\section{Regulamento técnico para medicamentos genéricos}

O Regulamento técnico para medicamentos genéricos descrito na RDC 84 determinou as medidas antecedentes ao seu registro, bem como os aspectos legais e técnicos, as medidas pós-registro e os critérios para prescrição e dispensação dos medicamentos genéricos. Foram citados, ainda, os casos onde há exigência de novos ensaios de bioequivalência, sendo reapresentada a lista dos medicamentos não aceitos como genéricos. A RDC 84 foi revogada pela RDC 135, de 29 de maio de 2003 (16).

A RDC 135 seguiu o mesmo formato da anterior, porém foi mais detalhada, contendo as seguintes informações: 1) registro de medicamentos importados;
2) apresentação de resultados dos estudos de estabilidade da formulação de maior concentração para formulações com três ou mais concentrações diferentes do mesmo fármaco; 3) estudos de estabilidade de longa duração para medicamentos cujo prazo de validade excedesse 24 meses; 5) possibilidade de registro para comprimidos revestidos cujo medicamento de referência fosse um comprimido simples ou vice-versa, desde que o revestimento não apresentasse função gastro-protetora; 6) recomendação da elaboração de relatório referente a testes biofarmacotécnicos para os medicamentos cujos estudos de bioequivalência podem ser substituídos pelo teste de equivalência farmacêutica (16).

Em 2 de março de 2007 foi aprovada a RDC 16, revogando-se a RDC 135. Sua inovação foi a permissão para que os contraceptivos orais e os hormônios endógenos de uso oral fossem registrados como genéricos. Ocorreram também modificações quanto à documentação necessária ao registro desses medicamentos. Além disso, foram adicionados os antieméticos, antitérmicos e antipiréticos, antibacterianos tópicos, antihemorroidários e descongestionantes nasais tópicos à lista dos medicamentos que não poderiam ser admitidos como genéricos (35).

\section{Rotulagem}

Em relação à rotulagem, a RDC 47, de 28 de março de 2001, ainda em vigor, estabelece que os medicamentos genéricos devem ser identificados com uma faixa amarela contendo a letra $\mathrm{G}$ em azul em suas embalagens externas (36).

\section{Normatização de centros prestadores de serviços}

Considerando-se a necessidade de normatizar as unidades que realizam os ensaios de equivalência farmacêutica, biodisponibilidade e bioequivalência de medicamentos, foi elaborada a RE 41 de 28 de abril de 2000. Essa resolução determina os critérios necessários às entidades que pretendam cadastrar-se junto à ANVISA para se habilitarem à realização dos ensaios em questão (37). Em maio de 2003, foi promulgada a RDC 103, que define os requisitos necessários e as funções dos centros de biodisponibilidade/bioequivalência de medicamentos, dos responsáveis por cada etapa, do coordenador do centro e do investigador principal. Apresenta, ainda, o procedimento de solicitação da Certificação em Boas Práticas de Biodisponibilidade/Bioequivalência de medicamentos, além do procedimento relacionado à terceirização de centro para realização da etapa clínica (38).

Em 28 de dezembro de 2006 foi publicada a RDC 221, a qual institui a Rede Brasileira de Centros Públicos de Equivalência Farmacêutica e Bioequivalência (REQBIO) (39). O objetivo dessa RDC foi buscar a excelência técnico-científica e fortalecer a interface entre esses centros e os laboratórios públicos oficiais produtores de medicamentos que abastecem o SUS. 


\section{Protocolo e relatório técnico de estudo de bioequivalência}

O Guia para protocolo e relatório técnico de estudo de bioequivalência foi descrito pela primeira vez na RE 479, de 19 de março de 2002, e expõe os dados que devem estar contidos no protocolo e no relatório técnico em questão. Entre esses dados estão informações sobre os pesquisadores e os medicamentos teste e referência, a seleção de voluntários e os dados sobre estudos de validação. A RE 479 foi revogada pela RE 894, de 29 de maio de 2003. A RE 894 contém a identificação dos responsáveis pela etapa analítica e estatística, os nomes e endereços das instalações em que foram desenvolvidas cada uma das etapas do estudo de bioequivalência e os critérios para estabelecimento dos desvios ocorridos nos protocolos $(40,41)$.

\section{Estudo e elaboração do relatório de equivalência farmacêutica}

O Guia para realização do estudo e elaboração do relatório de equivalência farmacêutica foi apresentado na RE 476, de 19 de março de 2002. Inclui os critérios para os estudos de equivalência farmacêutica dos medicamentos isentos da análise de bioequivalência, para aqueles nos quais a equivalência farmacêutica é aceita como indicativo da bioequivalência e para casos nos quais os medicamentos serão submetidos ao estudo de bioequivalência. A RE 476 foi revogada pela RE 900, de 29 de maio de 2003, que descreve os estudos de equivalência farmacêutica para medicamentos isentos do estudo de bioequivalência, como as apresentações em gotas e em spray. A RE 900, por sua vez, foi revogada pela RE 310, de 1 de setembro de 2004, que ainda se encontra em vigor $(17,42,43)$.

O Guia para realização do estudo e elaboração do relatório de equivalência farmacêutica e perfil de dissolução contido na atual RE 310 estabelece que estudos de equivalência farmacêutica e de perfis de dissolução devem ser realizados por laboratórios devidamente autorizados pela ANVISA para essas finalidades e pertencentes à Rede Brasileira de Laboratórios Analíticos em Saúde (Reblas). Os estudos de perfis de dissolução devem utilizar o mesmo método de dissolução empregado no estudo de equivalência farmacêutica. No caso da inexistência de método de dissolução farmacopeico, os perfis de dissolução devem ser realizados em pelo menos três meios de dissolução diferentes, dentro da faixa de $\mathrm{pH}$ fisiológico. A RE 310 cita também o método de comparação dos perfis de dissolução por meio dos parâmetros f1 (fator de diferença) e f2 (fator de semelhança) (17).

No Guia para ensaios de dissolução para formas farmacêuticas sólidas orais de liberação imediata (FFSOLI), descrito na RE 483, de 19 de março de 2002, são apresentadas as recomendações gerais para os ensaios de dissolução, as especificações relacionadas às características biofarmacêuticas de fármacos e os métodos estatísticos para a comparação de perfis de dissolução. Essa resolução foi revogada pela RE 901, de
29 de maio de 2003, a qual só difere da anterior quanto à correção da definição das variáveis envolvidas no cálculo do fator f1. A RE 901 também foi revogada pela RE 310. No entanto, a RE 310 não aborda as recomendações gerais para ensaios de dissolução nem especificações relacionadas às características biofarmacêuticas de fármacos, como fazia a RE 901 (17, 28, 43). Ou seja: com a elaboração da RE 310, a ANVISA compilou todas as informações sobre bioequivalência e dissolução em uma só legislação, não abrangendo, no entanto, todos os itens mencionados anteriormente.

\section{Provas de bioequivalência de medicamentos genéricos}

A RE 478, de 19 de março de 2002, referente ao Guia para provas de bioequivalência de medicamentos genéricos, estabeleceu que as etapas clínica, analítica e estatística dos estudos de bioequivalência devem seguir os seus respectivos guias (44).

\section{Validação de métodos analíticos}

O Guia para validação de métodos analíticos foi apresentado na RE 475, de 19 de março de 2002. Esse guia regulamenta as características a serem observadas durante a validação de procedimentos analíticos e bionalíticos. Traz também considerações específicas relevantes ao estudo de estabilidade do medicamento de uma forma geral e especificamente em líquidos biológicos. A RE 475 foi revogada pela RE 899, de 29 de maio de 2003, que apresenta as seguintes alterações: classificação dos testes analíticos em quatro categorias, de acordo com sua finalidade, separação dos critérios necessários para sua validação e especificação da utilização de, no mínimo, três curvas de calibração de concentração do fármaco próximas do suposto limite de quantificação para cálculo do desvio padrão. Apresenta ainda os fatores que devem ser considerados na determinação da robustez de métodos analíticos. Quanto aos métodos bioanalíticos, foram inseridas definições de termos usuais e do critério de aceitação da curva de calibração, cujo coeficiente de correlação linear foi alterado para ser igual ou superior a 0,98 , contra os 0,95 estabelecidos na RE 475, já revogada $(24,45)$.

\section{Correlação in vitrolin vitro}

Com relação a esse tema, havia apenas uma citação na RE 391, de 9 de agosto de 1999, dentro do item de critérios e condições para o registro e o controle de qualidade dos medicamentos genéricos. O guia para a realização desses estudos foi publicado pela primeira vez na RDC 10, sendo que as RDCs que a sucederam não apresentaram alterações significativas sobre esse assunto $(3,15)$. A RE 482, de 19 de março de 2002, atualmente em vigor, contém o Guia para estudos de CIVIV, o qual apresenta o conceito e os níveis de correlação A, B e C, com suas respectivas características. Expõe também o procedimento que pode ser utilizado como orientação para o desenvolvimento de correlação de nível A, além 
de estabelecer as especificações para o estudo de dissolução utilizando os processos de convolução/deconvolução. No método de convolução, a projeção ou antecipação de dados para elaboração de curvas de níveis plasmáticos é realizada a partir de resultados de um estudo de dissolução. Já a deconvolução permite que dados aceitáveis de níveis plasmáticos sejam utilizados para estabelecer as especificações superiores e inferiores de dissolução em cada tempo (46).

\section{Elaboração de relatório técnico de estudo de biodisponibilidade relativa/bioequivalência}

O Guia para elaboração de relatório técnico de estudo de biodisponibilidade relativa/bioequivalência, contido na RE 895, de 29 de maio de 2003, descreve os dados que devem ser incluídos no relatório técnico do estudo em questão, especificando o que é requerido quanto a informações gerais e relatórios clínico, analítico e estatístico (30).

\section{Desenhos aplicáveis a estudos de bioequivalência}

Esse tema foi descrito inicialmente na RE 484, de 19 de março de 2002. A RE 484 foi revogada pela RE 898, de 29 de maio de 2003, a qual apresenta o Guia para planejamento e realização da etapa estatística de estudos de biodisponibilidade relativa/bioequivalência, além de fornecer os desenhos que já haviam sido apresentados na resolução revogada. Também descreve as recomendações gerais para análise estatística pertinente ao estudo $(47,48)$.

\section{Isenção e substituição de estudos de bioequivalência}

O Guia para isenção e substituição de estudos de bioequivalência, apresentado na RE 481, de 19 de março de 2002, listou os tipos de medicamentos que não requerem estudos de bioequivalência. A RE 481 foi revogada pela RE 897, de 29 de maio de 2003, que difere da anterior apenas por acrescentar ao grupo de isentos de estudos de bioequivalência as cápsulas ou comprimidos de liberação modificada (retardada ou prolongada), com várias dosagens, mesma forma farmacêutica, formulações proporcionais, mesmo mecanismo de liberação do fármaco, fabricados pelo mesmo produtor, no mesmo local de fabricação $(33,49)$.

A partir da RE 896, de 29 de maio de 2003, foram realizadas atualizações visando ao esclarecimento de dificuldades quanto à execução das etapas clínica, analítica e estatística. A RE 896 foi revogada pela RE 397, de 12 de novembro de $2004(50,51)$. Essa, por sua vez, exclui a possibilidade de medir efeitos farmacodinâmicos de medicamentos cujas concentrações são baixas no sangue durante a etapa clínica. Por outro lado, inclui a necessidade de determinação da depuração e do volume de distribuição aparente na etapa estatística. A RE 397 foi revogada pela RE 1 170, de 19 de abril de 2006, que ainda está em vigor (23). A RE 1170 altera os seguintes aspectos em relação à anterior: informa sobre a realização da etapa clínica de medicamentos transdérmicos, formas farmacêuticas de depósito e adesivos transdérmicos. Apresenta também correção nos casos em que são recomendados estudos com alimentos para as formas farmacêuticas de uso oral. Corrige, ainda, o aspecto de que os estudos de doses múltiplas devem ser realizados para reduzir a variabilidade intraindividual e não inter-individual, como apresentado na resolução revogada. Finalmente, houve a adição de considerações a respeito da quantificação de substâncias endógenas na etapa analítica e na etapa estatística.

\section{Medicamentos similares}

Com relação aos medicamentos similares houve, também, uma evolução histórica, tal como ocorreu com o medicamento genérico. A primeira disposição a respeito do produto similar foi a instrução normativa 1, de 30 de dezembro de 1994 (52), revogada pela RDC 157 de 31 de maio de 2002 (53), que estabeleceu os requisitos para estudos de equivalência farmacêutica para medicamentos similares. Em 29 de maio de 2003, foram publicadas a RDC 133 (8), aprovando o Regulamento técnico para registro de medicamentos similares, e a RDC 134, que dispôs sobre a adequação dos medicamentos similares já registrados (9). Ambas incluíram a obrigatoriedade de os similares serem submetidos a estudos de biodisponibilidade relativa. A RDC 133 revogou a RDC 157 que, por sua vez, foi revogada pela RDC 17, de 3 de março de 2007, ainda em vigor, e que traz o Regulamento técnico para medicamentos similares $(8,54)$. Vale, no entanto, ressaltar que o medicamento similar ainda não pode ser considerado intercambiável com o medicamento de referência, tendo em vista o prazo de adequação do mercado brasileiro de medicamentos similares à nova legislação.

\section{DISCUSSÃO}

A implantação da política de genéricos no Brasil, iniciada em 1999, meses após a criação da ANVISA, refletiu um esforço do Ministério da Saúde de reduzir significativamente os custos da terapia farmacológica através dos medicamentos genéricos, possibilitando acesso de maior parcela da população aos tratamentos. Além disso, a instituição de uma política de genéricos visava também disponibilizar ao mercado brasileiro medicamentos com qualidade assegurada, tendo em vista sua intercambialidade com o medicamento de referência que, em geral, corresponde ao medicamento inovador registrado após a comprovação de sua eficácia e segurança.

Entretanto, após a promulgação da Lei dos Genéricos, foi necessária a sua regulamentação técnica para normatizar os procedimentos adequados aos estudos de bioequivalência. Após essa primeira regulamentação, observou-se que a ANVISA adotou um processo de revisão constante, que culminou na publicação de novas resoluções que visavam à introdução 
de novos procedimentos ou ao aprimoramento daqueles já existentes.

Os primeiros medicamentos genéricos registrados foram, em sua maioria, soluções injetáveis administradas por via intravascular ou soluções orais que estavam isentas da realização do estudo in vivo, e que podiam ser registradas mediante o cumprimento da equivalência farmacêutica (in vitro), entre outros requisitos. Tal fato demonstrou que houve um período de adaptação, para permitir o estabelecimento de centros prestadores de serviço que realizam os ensaios de bioequivalência.

Após 3 anos decorridos dos primeiros registros, observou-se que o preço dos genéricos era cerca de $40 \%$ menor em comparação aos medicamentos de referência. Houve redução de 37 a $65 \%$ dos custos para o tratamento das seguintes enfermidades: hipertensão, diabetes, colesterol, gota, câncer de próstata e glaucoma (55).

Embora outros países do mundo, como os Estados Unidos, tenham sido pioneiros na implantação dos medicamentos genéricos, a ANVISA tem realizado atualizações frequentes na legislação brasileira, o que torna as regulamentações equiparáveis às promulgadas por renomadas agências internacionais, como a FDA, European Medicines Agency (EMA) e Health Canada, e pela Organização Mundial de Saúde (OMS). Nos últimos anos, também tem sido realizada a inclusão de temas importantes e de debates com as principais agências mundiais, visando a atualizar e ampliar as normatizações dos testes necessários ao cumprimento dos requisitos de equivalência farmacêutica, bioequivalência, biodisponibilidade relativa, comparação de perfis de dissolução e CIVIV quanto à possibilidade de bioisenção para o registro.

Quanto à aceitação dos medicamentos genéricos pela população, cabe ressaltar que o crescimento de suas vendas nos primeiros 18 meses de sua introdução no mercado foi em torno de $15 \%$ ao mês. Entre junho de 2000 e agosto de 2001, a venda de genéricos cresceu $249,42 \%$, chegando a 7,06 milhões de unidades. Desde a RE 74, de 2000, o número de genéricos registrados e comercializados tem crescido amplamente. Em abril de 2004, havia 1124 medicamentos genéricos registrados, divididos em 270 fármacos e 57 classes terapêuticas, que atendiam a $60 \%$ das necessidades de prescrição. Consequentemente, o perfil de consumo de medicamentos no mercado brasileiro alterou-se. Segundo uma empresa dedicada ao acompanhamento do mercado farmacêutico global, entre dezembro de 2000 e novembro de 2002 ocorreu uma rápida e grande evolução na participação dos genéricos no mercado brasileiro, um pequeno declínio nas vendas dos medicamentos de referência e uma forte queda nas vendas de medicamentos similares. A ANVISA, por sua vez, também verificou evolução da participação da quantidade vendida de medicamentos genéricos no Brasil (55).

Nos primeiros anos da implantação dos genéricos, a mídia impressa, acompanhando as transformações do mercado farmacêutico, noticiava uma queda nas vendas dos remédios de marca. Cálculos de algumas multinacionais indicavam uma queda de até $30 \%$ na venda dos produtos de referência em dezembro de 2002 (55).
Além disso, outra pesquisa por amostragem feita pela ANVISA mostrou que a comercialização não havia crescido em volume em $47 \%$ das farmácias pesquisadas, sugerindo uma simples migração do consumidor do medicamento de marca para o genérico.

O Brasil atingiu, em poucos anos, um patamar de vendas de genéricos que outros países demoraram várias décadas para alcançar. $\mathrm{O}$ sucesso na implantação dessa política pode ser atribuído a vários fatores, destacando-se a contínua adequação da legislação, o que também está de acordo com as recomendações da OMS em relação à necessidade de acompanhamento efetivo dos rumos da implantação de políticas nacionais de medicamentos pelas agências reguladoras.

A implantação da política de genéricos no Brasil, embora possa não ter correspondido a um aumento significativo no acesso da população aos medicamentos, pode ser considerada um ganho importante para a sociedade. Os consumidores passaram a contar com a oportunidade de comprar medicamentos a preços mais acessíveis, com garantia de qualidade, segurança, eficácia e intercambialidade com os medicamentos de referência.

Passados 10 anos da implantação dos genéricos no Brasil, ainda existem muitos avanços a serem realizados, principalmente quanto às normatizações de bioisenção e estudos de correlação in vitro/in vivo. Porém, o impacto da regulamentação dos genéricos alcançou também os procedimentos de registro dos medicamentos similares, o que corresponde a avanços na qualidade e segurança no uso de todos os medicamentos não inovadores no País.

Outros ganhos relacionados a essa implantação relacionam-se ao aumento da oferta de postos de trabalho na indústria farmacêutica, em áreas tais como desenvolvimento farmacotécnico, controle e garantia de qualidade e assuntos regulatórios. Há também uma crescente demanda por profissionais especializados para atuar em centros de equivalência farmacêutica e bioequivalência, ou como monitores de bioequivalência contratados pelas empresas que pretendem registrar genéricos ou adequar seus similares à regulamentação vigente.

\section{CONCLUSÃO}

Na última década, a evolução dos aspectos técnicos da regulamentação brasileira na área de medicamentos, tendo como base princípios científicos, é inquestionável. A implantação das legislações contribuiu para o aprimoramento da fabricação e garantia de qualidade dos medicamentos no país, introduzindo conceitos tais como equivalência farmacêutica, biodisponibilidade e bioequivalência.

Os problemas relativos a biodisponibilidade, bioequivalência e intercambialidade recaem sobre medicamentos apresentados sob formas farmacêuticas para as quais existem muitos fatores que podem alterar a liberação, a dissolução e a absorção do fármaco no organismo, principalmente formas farmacêuticas sólidas administradas por via oral. Tais fatores devem ser am- 
plamente estudados durante o desenvolvimento farmacotécnico do produto, o que, no entanto, não exclui a necessidade da realização do teste de bioequivalência. Desse modo, o teste de bioequivalência é fundamental para garantir que dois medicamentos que comprovaram a equivalência farmacêutica apresentarão o mesmo desempenho no organismo em relação à biodisponibilidade, expressa em termos da quantidade absorvida do fármaco, a partir da forma farmacêutica administrada, e da velocidade do processo de absorção.

Estudos visando à bioisenção de novos candidatos a medicamentos genéricos, no Brasil, atualmente são realizados segundo a RE 897, a qual não emprega os conceitos relacionados ao SCB. No entanto, em 2009 houve a criação de um grupo de trabalho no âmbito da ANVISA com o objetivo de elaborar uma proposta de guia sobre isenção e substituição dos estudos de bioequivalência, contendo uma relação de fármacos candidatos a bioisenção. Esse guia seria pautado pelo SCB, o que traz nova perspectiva para o registro de formas sólidas orais de liberação imediata que contenham fármacos da classe I (56).

Por meio da avaliação das resoluções publicadas pela ANVISA até o momento, verifica-se que houve várias alterações, ao longo do tempo, no sentido de otimizar a implementação da política de medicamentos genéricos e viabilizar o processo de adequação dos medicamentos similares no Brasil, o que representou grande avanço técnico-científico para o País.

Agradecimentos. Ao Programa de Pós-Graduação em Ciências Farmacêuticas (CiPharma/EF-UFOP) e Fundação de Amparo à pesquisa de Minas Gerais (FAPEMIG). À Universidade Federal de Ouro Preto
(UFOP), ao Conselho Nacional de Desenvolvimento Científico e Tecnológico (CNPQ) e à Coordenação de Aperfeiçoamento de Pessoal de Nível Superior (CAPES) pelo suporte financeiro mediante bolsas de estudo às mestrandas.

\section{SYNOPSIS}

\section{Generic drugs in Brazil: historical overview and legislation}

The Brazilian generic drugs policy was implemented in 1999 with the aim of stimulating competition in the market, improve the quality of drugs and improve the access of the population to drug treatment. The process of implementing this policy allowed the introduction and discussion of concepts that had never before been used in the context of drug registration in Brazil: bioavailability, bioequivalence, pharmaceutical equivalence, generic drugs, biopharmaceutical classification system, biowaiver. The present article provides definitions for these concepts in the context of Brazilian legislation as well as a historical and chronological description of the implementation of the generic drugs policy in Brazil, including a list of current generic drug legislation. This article contributes to the understanding of the Brazilian generic drugs policy and facilitates the search for information concerning the legal requirements for registration of drugs in Brazil.

Key words: therapeutic equivalency; biological availability; drugs, generic; legislation; Brazil.

\section{REFERÊNCIAS}

1. Dias CRC, Romano-Lieber NS. Processo da implantação da política de medicamentos genéricos no Brasil. Cad Saude Publica. 2006;22(8):1661-69.

2. Brasil. Lei 9 787/1999. Disponível em: www.anvisa.gov.br/hotsite/genericos/ legis/leis/9787.htm. Acessado em 12 de dezembro de 2008

3. Brasil. Resolução 391/1999. Disponível em: www.anvisa.gov.br/hotsite/gener icos/legis/resolucoes/391_99.htm. Acessado em 12 de dezembro de 2008.

4. Brasil. Lei 6 360/1976. Disponível em: www.anvisa.gov.br/hotsite/genericos/ legis/leis/9787.htm. Acessado em 12 de dezembro de 2008.

5. Brasil. Lei 9 279/1996. Disponível em: http://www.inpi.gov.br/menuesquerdo/patente/pasta_legislacao/ Lei9279.pdf. Acessado em 12 de dezembro de 2008.

6. Consiglieri VO, Storpirtis S. Biodisponibilidade e bioequivalência de medicamentos: aspectos fundamentais para o planejamento e execução de estudos. Rev Bras Cienc Farm. 2000;36(1):13-21.

7. Storpirtis S, Bueno MM. A vigilância sanitária e a política nacional de medicamentos no Brasil: medicamentos genéricos, similares e novos. Em: Storpirtis S, Mori ALPM, Yochiy A, Ribeiro E, Porta V. Farmácia clínica e atenção farmacêutica. Rio de Janeiro: Guanabara Koogan; 2008. Pp. 25-36.

8. Brasil. Resolução RDC 133/2003. Disponível em: e-legis.bvs.br/leisref/ public/showAct.php. Acessado em 23 de março de 2009.

9. Brasil. Resolução RDC 134/2003. Disponível em: e-legis.bvs.br/leisref/public/showAct. php. Acessado em 23 de março de 2009.

10. Bueno MM, Storpirts S. Aspectos regulatórios e perspectivas para o registro e o pós-registro de medicamentos genéricos e similares no Brasil. Em: Storpirtis S, Gonçalves, JE, Chiann C, Gai MN. Biofarmacotécnica. Rio de Janeiro: Guanabara Koogan; 2009. Pp. 231-43.
11. Antunes A, Magalhães JL, orgs. Oportunidades em medicamentos genéricos-A indústria farmacêutica brasileira. Rio de Janeiro: Editora Interciência; 2008.

12. Oliveira EA, Labra ME, Bermudez J. A produção pública de medicamentos no Brasil. Cad Saude Publica 2006;22(11): 2379-89.

13. Magalhães JL, Boechat N, Antunes AMS. Principales desafíos de la producción pública de medicamentos en Brasil y panorama del sistema de salud. Rev Cub Salud Publica. 2008;34(3)19-25.

14. Rodrigues WCV, Soler O. Licença compulsória do efavirenz no Brasil em 2007: contextualização. Rev Panam Salud Publica. 2009;26(6):553-9.

15. Brasil. Resolução RDC 10/1991. Disponível em: www.anvisa.gov.br/hotsite/ genericos/legis/resolucoes/10_01rdc. $\mathrm{htm}$. Acessado em 12 de dezembro de 2008.

16. Brasil. Resolução RDC 135/2003. Disponível em: www.anvisa.gov.br/ 
legis/resol/2003/rdc/135_03rdc. $\mathrm{htm}$. Acessado em 15 de dezembro de 2008.

17. Brasil. Resolução RE 310/2004 Disponível em: e-legis.anvisa.gov.br/ leisref/public/showAct.php?id15466\& word $=$. Acessado em 12 de dezembro de 2008.

18. Marques MRC. Dissolução de medicamentos. Em: Storpirtis S, Gonçalves JE Chiann C, Gai MN. Biofarmacotécnica. Rio de Janeiro: Guanabara Koogan; 2009. Pp. 96-108.

19. Brasil, Agência Nacional de Vigilância Sanitária. Publicações. Disponível em: www.anvisa.gov.br/divulga/public/ index.htm. Acessado em 12 de dezembro de 2008.

20. Midha KK, Rawson MJ, Hubbarb JW. Bioequivalence: switchability and scaling. Eur J Pharm Sci. 1998;6(2):81-91.

21. Storpirtis S, Marcolongo R, Gasparotto FS, Villanova CM. A equivalência farmacêutica no contexto da intercambialidade entre medicamentos genéricos e de referência: bases técnicas e científicas. Brasília: ANVISA; 2004. Disponível em: www.anvisa.gov.br/divulga/artigos/ genericos_referencia.pdf. Acessado em 12 de dezembro de 2008.

22. Estados Unidos, U. S. Department of Health and Human Services, Food and Drug Administration. Center of Drug Evaluation and Research (CDER). Guidance for industry: bioavailability and bioequivalence studies for orally administered drug products-general considerations, 2003. Disponível em: www.fda. gov/downloads/Drugs/Guidance ComplianceRegulatoryInformation/ Guidances/ucm070124.pdf. Acessado em 24 de março de 2009.

23. Brasil. Resolução RE 1 170/2006. Disponível em: e-legis.anvisa.gov.br/ leisref/public/showAct.php. Acessado em 12 de dezembro de 2008.

24. Brasil. Resolução RE 899/2003. Disponível em: www.anvisa.gov.br/ legis/resol/2003/re/899_03re.htm. Acessado em 15 de dezembro de 2008.

25. Brasil. Resolução RE 476/2002. Disponível em: www.anvisa.gov.br/ legis/resol/2002/476_02re.htm. Acessado em 12 de dezembro de 2008.

26. Amidon GL, Lennernäs $H$, Shah VP, Crison JR. A theoretical basis for a biopharmaceutical drug classification: the correlation of in vitro drug product dissolution and in vivo bioavailability. Pharm Res. 1995;12(3):413-20.

27. Estados Unidos, U. S. Department of Health and Human Services, Food and Drug Administration. Center of Drug Evaluation and Research (CDER). Guidance for industry: extended release oral dosage forms: development, evaluation, and application of in vitro in vivo correlations, 1997. Disponível em: www.fda. gov/downloads/Drugs/Guidance
ComplianceRegulatoryInformation/ Guidances/ucm070239.pdf. Acessado em 24 de março de 2009.

28. Brasil. Resolução RE 901/2003. Disponível em: www.anvisa.gov.br/ legis/resol/2003/re/901_03re.htm. Acessado em 15 de dezembro de 2008.

29. Amidon GL, Lennernas H, Shah VP, Crison JR. A theoretical basis for a biopharmaceutic drug classification: the correlation of in vitro drug product dissolution and in vivo bioavailability. Pharm Res. 1995;12(3):413-20.

30. Brasil. Resolução RE 895. Disponível em: www.anvisa.gov.br/legis/resol/2003/ re/895_03re.htm Acessado em 15 de dezembro de 2008.

31. Cutler DJ, Beyssac E, Aiache JM. Level B and $C$ in vivo/in vitro correlations: statistical considerations. Int J Pharm. 1997; 158:185-93.

32. Rao BS, Seshasayana A, Saradhi SVP, Kumar NR, Narayan CPS, Murthy KVR. Correlation of 'in vitro' release and 'in vivo' absorption characteristics of rifampicin from ethylcellulose coated nonpareil beads. Int J Pharm. 2001; 230:1-9.

33. Brasil. Resolução RE 897/2003. Disponível em: www.anvisa.gov.br/ legis/resol/2003/re/897_03re.htm. Acessado em 15 de dezembro de 2008.

34. Brasil. Resolução RDC 84/2002. Disponível em: www.anvisa.gov.br/legis/ resol/2002/84_02rdc_versao2.htm. Acessado em 12 de dezembro de 2008.

35. Brasil. Resolução RDC 16/2007. Disponível em: e-legis.bvs.br/leisref/ public/showAct.php. Acessado em 23 de março de 2009.

36. Brasil. Resolução RDC 47/2001. Disponível em: www.anvisa.gov.br/ hotsite/genericos/legis/resolucoes/ 47_01rdc.htm. Acessado em 12 de dezembro de 2008.

37. Brasil. Resolução RE 41/2000. Disponível em: www.anvisa.gov.br/ legis/resol/2000/41_00.htm. Acessado em 12 de dezembro de 2008.

38. Brasil. Resolução RDC 103/2003. Disponível em: www.anvisa.gov.br/ legis/resol/2003/rdc/103_03rdc.htm. Acessado em 15 de dezembro de 2008.

39. Brasil. Resolução RDC 221/2006 Disponível em: www.anvisa.gov.br/ legis/resol/2006/rdc/221_06.pdf. Acessado em 23 de março de 2009.

40. Brasil. Resolução RE 479/2002. Disponível em: www.anvisa.gov.br/ legis/resol/2002/479_02re.htm. Acessado em 12 de dezembro de 2008.

41. Brasil. Resolução RDC 894/2003. Disponível em: e-legis.bvs.br/leisref/ public/showAct.php. Acessado em 15 de dezembro de 2008.

42. Brasil. Resolução RE 900/2003. Disponível em: www.anvisa.gov.br/ legis/resol/2003/re/900_03re.htm Acessado em 15 de dezembro de 2008.
43. Brasil. Resolução RE 483/2002. Disponível em: www.anvisa.gov.br/ legis/resol/2002/483_02re.htm. Acessado em 12 de dezembro de 2008.

44. Brasil. Resolução RE 478/2002. Disponível em: www.anvisa.gov.br/ legis/resol/2002/478_02re.htm. Acessado em 12 de dezembro de 2008.

45. Brasil. Resolução RE 475/2002. Disponível em: www.anvisa.gov.br/ legis/resol/2002/475_02re.htm. Acessado em 12 de dezembro de 2008.

46. Brasil. Resolução RE 482/2002. Disponível em: www.anvisa.gov.br/ legis/resol/2002/482_02re.htm. Acessado em 12 de dezembro de 2008.

47. Brasil. Resolução RE 484/2002. Disponível em: www.anvisa.gov.br/ hotsite/genericos/legis/resolucoes / 2002/484_02re.htm. Acessado em 12 de dezembro de 2008.

48. Brasil. Resolução RE 898/2003 Disponível em: www.anvisa.gov.br/ legis/resol/2003/re/898_03re.htm. Acessado em 15 de dezembro de 2008.

49. Brasil. Resolução RE 481/2002. Disponível em: www.anvisa.gov.br/ hotsite/genericos/legis/resolucoes/ 2002/481 02re.htm. Acessado em 12 de dezembro de 2008.

50. Brasil. Resolução RE 896/2003. Disponível em: www.anvisa.gov.br/ legis/resol/2003/re/896_03re.htm. Acessado em 15 de dezembro de 2008.

51. Brasil. Resolução RE 397/2004. Disponível em: e-legis.ANVISA.gov. br/leisref/public/showAct.php. Acessado em 12 de dezembro de 2008.

52. Brasil. Ministério da Saúde. Instrução normativa 1. Brasília: Ministério da Saúde; 2010. Disponível em: e-legis. anvisa.gov.br/leisref/public/showAct. php. Acessado em 23 de março de 2009.

53. Brasil. Resolução RDC $157 / 2002$. Disponível em: e-legis.bvs.br/leisref/ public/showAct.php. Acessado em 23 de março de 2009.

54. Brasil. Resolução RDC 17/2007. Disponível em: e-legis.bvs.br/leisref/ public/showAct.php. Acessado em 23 de março de 2009.

55. Hasenclaver L. O mercado de medicamentos genéricos no Brasil. Brasília: Simpósio Franco-Brasileiro "O Novo Direito da Propriedade Intelectual no Domínio da Saúde e dos Seres Vivos (implicações para o acesso aos tratamentos anti-retrovirais); 2004. Disponível em: http://www.deol honaspatentes.org.br/media/file/ Patentes/hasenclever_ufrj_\%20 mercado_medica mentos_genericos.PDF. Acessado em 30 de março de 2009.

56. Brasil. Portaria 1 143. Diário Oficial da União (DOU) 2009. 25 de setembro: 185(2):61.

Manuscrito recebido el 30 de dezembro de 2009 Aceito en versão revisada el 17 setembro de 2010. 
ANEXO 1. Legislações publicadas pela Agência Nacional de Vigilância Sanitária com relação aos medicamentos genéricos, Brasil, 1999 a 2010

\begin{tabular}{|c|c|c|c|}
\hline Legislação & Assunto & Revogada por & URL \\
\hline $\begin{array}{l}\text { Lei } 9787 \text { de } 10 \text { de } \\
\text { fevereiro de } 1999\end{array}$ & $\begin{array}{l}\text { Altera a lei } 6360 \text { de 1976, que dispõe sobre a } \\
\text { vigilância sanitária }\end{array}$ & Em vigor & $\begin{array}{l}\text { http://www.anvisa.gov.br/ } \\
\text { legis/leis/9787_99.htm }\end{array}$ \\
\hline $\begin{array}{l}\text { Resolução } 391 \text { de } 9 \\
\text { de agosto de } 1999\end{array}$ & Regulamento técnico para medicamentos genéricos & $\begin{array}{l}\text { RDC } 135 \text { de } 29 \text { de } \\
\text { maio de } 2003\end{array}$ & $\begin{array}{l}\text { http://www.anvisa.gov.br/ } \\
\text { legis/resol/2003/rdc/135_03rdc.htm }\end{array}$ \\
\hline $\begin{array}{l}\text { RE } 41 \text { de } 28 \text { de abril } \\
2000\end{array}$ & $\begin{array}{l}\text { Faz determinações para as entidades ou empresas } \\
\text { que pretendam se habilitar para a realização dos } \\
\text { ensaios de equivalência farmacêutica, biodisponibili- } \\
\text { dade e/ou bioequivalência em medicamentos }\end{array}$ & Em vigor & $\begin{array}{l}\text { http://www.anvisa.gov.br/ } \\
\text { legis/resol/2000/41_00.htm }\end{array}$ \\
\hline $\begin{array}{l}\text { RDC } 10 \text { de } 2 \text { de } \\
\text { janeiro de } 2001\end{array}$ & Regulamento técnico para medicamentos genéricos & $\begin{array}{l}\text { RDC } 84 \text { de } 19 \text { de } \\
\text { março de } 2002\end{array}$ & $\begin{array}{l}\text { http://www.anvisa.gov.br/ } \\
\text { legis/resol/2002/84_02rdc.htm }\end{array}$ \\
\hline $\begin{array}{l}\text { RDC } 47 \text { de } 28 \text { de } \\
\text { março de } 2001\end{array}$ & $\begin{array}{l}\text { Determina que os medicamentos genéricos } \\
\text { registrados ou que vierem a ser registrados junto à } \\
\text { ANVISA devem ter, em suas embalagens, o logotipo } \\
\text { que identifica o medicamento genérico }\end{array}$ & Em vigor & $\begin{array}{l}\text { http://www.anvisa.gov.br/ } \\
\text { legis/resol/47_01rdc.htm }\end{array}$ \\
\hline $\begin{array}{l}\text { RE } 476 \text { de } 19 \text { de } \\
\text { março de } 2002\end{array}$ & $\begin{array}{l}\text { Guia para realização do estudo e elaboração do } \\
\text { relatório de equivalência farmacêutica }\end{array}$ & $\begin{array}{l}\text { RE } 900 \text { de } 29 \text { de } \\
\text { maio de } 2003\end{array}$ & $\begin{array}{l}\text { http://www.anvisa.gov.br/ } \\
\text { legis/resol/2003/re/900_03re.htm }\end{array}$ \\
\hline $\begin{array}{l}\text { RDC } 84 \text { de } 19 \text { de } \\
\text { março de } 2002\end{array}$ & Regulamento técnico para medicamentos genéricos & $\begin{array}{l}\text { RDC } 135 \text { de } 29 \text { de } \\
\text { maio de } 2003\end{array}$ & $\begin{array}{l}\text { http://www.anvisa.gov.br/ } \\
\text { legis/resol/2003/rdc/135_03rdc.htm }\end{array}$ \\
\hline $\begin{array}{l}\text { RDC } 479 \text { de } 19 \text { de } \\
\text { março de } 2002\end{array}$ & $\begin{array}{l}\text { Guia para protocolo e relatório técnico de estudo de } \\
\text { bioequivalência }\end{array}$ & $\begin{array}{l}\text { RE } 894 \text { de } 29 \text { de } \\
\text { maio de } 2003\end{array}$ & $\begin{array}{l}\text { http://www.anvisa.gov.br/ } \\
\text { legis/resol/2003/re/894_03re.htm }\end{array}$ \\
\hline $\begin{array}{l}\text { RDC } 478 \text { de } 19 \text { de } \\
\text { março de } 2002\end{array}$ & $\begin{array}{l}\text { Guia para provas de bioequivalência de } \\
\text { medicamentos genéricos }\end{array}$ & Em vigor & $\begin{array}{l}\text { http://www.anvisa.gov.br/ } \\
\text { legis/resol/2002/478_02re.htm }\end{array}$ \\
\hline $\begin{array}{l}\text { RE } 482 \text { de } 19 \text { de } \\
\text { março de } 2002\end{array}$ & $\begin{array}{l}\text { Guia para estudos de correlação in vitro/in vivo } \\
\text { (CIVIV) }\end{array}$ & Em vigor & $\begin{array}{l}\text { http://www.anvisa.gov.br/ } \\
\text { legis/resol/2002/482_02re.htm }\end{array}$ \\
\hline $\begin{array}{l}\text { RE } 481 \text { de } 19 \text { de } \\
\text { março de } 2002\end{array}$ & $\begin{array}{l}\text { Guia para isenção e substituição de estudos de } \\
\text { bioequivalência }\end{array}$ & $\begin{array}{l}\text { RE } 897 \text { de } 29 \text { de } \\
\text { maio de } 2003\end{array}$ & $\begin{array}{l}\text { http://www.anvisa.gov.br/ } \\
\text { legis/resol/2003/re/897_03re.htm }\end{array}$ \\
\hline $\begin{array}{l}\text { RE } 484 \text { de } 19 \text { de } \\
\text { março de } 2002\end{array}$ & $\begin{array}{l}\text { Guia para desenhos aplicáveis a estudos de } \\
\text { bioequivalência }\end{array}$ & $\begin{array}{l}\text { RE } 898 \text { de } 29 \text { de } \\
\text { maio de } 2003\end{array}$ & $\begin{array}{l}\text { http://www.anvisa.gov.br/ } \\
\text { legis/resol/2003/re/898_03re.htm }\end{array}$ \\
\hline $\begin{array}{l}\text { RE } 475 \text { de } 19 \text { de } \\
\text { março de } 2002\end{array}$ & Guia para validação de métodos analíticos & $\begin{array}{l}\text { RE } 899 \text { de } 29 \text { de } \\
\text { maio de } 2003\end{array}$ & $\begin{array}{l}\text { http://www.anvisa.gov.br/ } \\
\text { legis/resol/2003/re/899_03re.htm }\end{array}$ \\
\hline $\begin{array}{l}\text { RE } 483 \text { de } 19 \text { de } \\
\text { março de } 2002\end{array}$ & $\begin{array}{l}\text { Guia para ensaios de dissolução para formas } \\
\text { farmacêuticas sólidas orais de liberação imediata } \\
\text { (FFSOLI) }\end{array}$ & $\begin{array}{l}\text { RE } 901 \text { de } 29 \text { de } \\
\text { maio de } 2003\end{array}$ & $\begin{array}{l}\text { http://www.anvisa.gov.br/ } \\
\text { legis/resol/2003/re/901_03re.htm }\end{array}$ \\
\hline $\begin{array}{l}\text { RDC } 103 \text { de } 8 \text { de } \\
\text { maio de } 2003\end{array}$ & $\begin{array}{l}\text { Os centros que realizam estudos de } \\
\text { biodisponibilidade/bioequivalência para fins de } \\
\text { registro de medicamentos deverão observar as } \\
\text { normas e regulamentos técnicos em vigor }\end{array}$ & Em vigor & $\begin{array}{l}\text { http://www.anvisa.gov.br/legis/ } \\
\text { resol/2003/rdc/103_03rdc.htm }\end{array}$ \\
\hline $\begin{array}{l}\text { RDC } 135 \text { de } 29 \text { de } \\
\text { maio de } 2003\end{array}$ & Regulamento técnico para medicamentos genéricos & $\begin{array}{l}\text { RDC } 16 \text { de } 2 \text { de } \\
\text { março de } 2007\end{array}$ & $\begin{array}{l}\text { http://www.crfsp.org.br/joomla/index. } \\
\text { php?option=com_content\&view= } \\
\text { article\&id=614\%3Aresolucao-rdc-no- } \\
\text { 16-de-02-de-marco-de-2007\&catid= } \\
\text { 113\%3Alegislacao\&ltemid=75 }\end{array}$ \\
\hline $\begin{array}{l}\text { RDC } 900 \text { de } 29 \text { de } \\
\text { maio de } 2003\end{array}$ & $\begin{array}{l}\text { Guia para realização do estudo e elaboração do } \\
\text { relatório de equivalência farmacêutica }\end{array}$ & $\begin{array}{l}\text { RE } 310 \text { de } 1^{\circ} \text { de } \\
\text { setembro de } 2004\end{array}$ & $\begin{array}{l}\text { http://www.interfarma.org.br/site2/ } \\
\text { images/Site\%20Interfarma/Informaco } \\
\text { esdosetor/RE/Registro/2004/ } \\
\text { RE\%20setembro\%20310- } \\
\text { 04\%20SIMILAR.pdf }\end{array}$ \\
\hline $\begin{array}{l}\text { RE } 895 \text { de } 29 \text { de } \\
\text { maio de } 2003\end{array}$ & $\begin{array}{l}\text { Guia para elaboração de relatório técnico de estudo } \\
\text { de biodisponibilidade relativa/ bioequivalência }\end{array}$ & Em vigor & $\begin{array}{l}\text { http://www.anvisa.gov.br/ } \\
\text { legis/resol/2003/re/895_03re.htm }\end{array}$ \\
\hline
\end{tabular}

(contínua) 
ANEXO 1. (continuação)

\begin{tabular}{|c|c|c|c|}
\hline Legislação & Assunto & Revogada por & URL \\
\hline $\begin{array}{l}\text { RE } 894 \text { de } 29 \text { de } \\
\text { maio de } 2003\end{array}$ & $\begin{array}{l}\text { Guia para protocolo e relatório técnico de estudo de } \\
\text { bioequivalência }\end{array}$ & Em vigor & $\begin{array}{l}\text { http://www.anvisa.gov.br/ } \\
\text { legis/resol/2003/re/894_03re.htm }\end{array}$ \\
\hline $\begin{array}{l}\text { RE } 899 \text { de } 29 \text { de } \\
\text { maio de } 2003\end{array}$ & $\begin{array}{l}\text { Guia para validação de métodos analíticos e } \\
\text { bioanalíticos }\end{array}$ & Em vigor & $\begin{array}{l}\text { http://www.anvisa.gov.br/ } \\
\text { legis/resol/2003/re/899_03re.htm }\end{array}$ \\
\hline $\begin{array}{l}\text { RE } 898 \text { de } 29 \text { de } \\
\text { maio de } 2003\end{array}$ & $\begin{array}{l}\text { Guia para planejamento e realização da etapa } \\
\text { estatística de estudos de biodisponibilidade } \\
\text { relativa/bioequivalência }\end{array}$ & Em vigor & $\begin{array}{l}\text { http://www.anvisa.gov.br/ } \\
\text { legis/resol/2003/re/898_03re.htm }\end{array}$ \\
\hline $\begin{array}{l}\text { RE } 901 \text { de } 29 \text { de } \\
\text { maio de } 2003\end{array}$ & $\begin{array}{l}\text { Guia para ensaios de dissolução para formas } \\
\text { farmacêuticas sólidas orais de liberação imediata } \\
\text { (FFSOLI) }\end{array}$ & $\begin{array}{l}\text { RE } 310 \text { de } 1 \text { de } \\
\text { setembro de } 2004\end{array}$ & $\begin{array}{l}\text { http://www.interfarma.org.br/site2/ } \\
\text { images/Site\%20Interfarma/Informaco } \\
\text { esdosetor/RE/Registro/2004/ } \\
\text { RE\%20setembro\%20310- } \\
\text { 04\%20SIMILAR.pdf }\end{array}$ \\
\hline $\begin{array}{l}\text { RE } 896 \text { de } 29 \text { de } \\
\text { maio de } 2003\end{array}$ & $\begin{array}{l}\text { Guia para provas de biodisponibilidade relativa/ } \\
\text { bioequivalência de medicamentos }\end{array}$ & $\begin{array}{l}\text { RE } 397 \text { de } 12 \text { de } \\
\text { novembro de } 2004\end{array}$ & $\begin{array}{l}\text { http://www.interfarma.org.br/site2/ } \\
\text { images/Site\%20Interfarma/Informaco } \\
\text { esdosetor/RE/Registro/2004/ } \\
\text { RE\%20novembro\%20397-04.pdf }\end{array}$ \\
\hline $\begin{array}{l}\text { RE } 897 \text { de } 29 \text { de } \\
\text { maio de } 2003\end{array}$ & $\begin{array}{l}\text { Guia para isenção e substituição de estudos de } \\
\text { bioequivalência }\end{array}$ & Em vigor & $\begin{array}{l}\text { http://www.anvisa.gov.br/ } \\
\text { legis/resol/2003/re/897_03re.htm }\end{array}$ \\
\hline $\begin{array}{l}\text { RE } 310 \text { de } 1 \text { de } \\
\text { setembro de } 2004\end{array}$ & $\begin{array}{l}\text { Guia para realização do estudo e elaboração do } \\
\text { relatório de equivalência farmacêutica e perfil de } \\
\text { dissolução }\end{array}$ & Em vigor & $\begin{array}{l}\text { http://portal.anvisa.gov.br/wps/wcm/ } \\
\text { connect/875f3a80419774c98d73ad } \\
\text { 925ac4fc61/RE_310_2004_- } \\
\text { Equivalencia_e_Perfil_dissolucao.pdf } \\
\text { ?MOD=AJPERES }\end{array}$ \\
\hline $\begin{array}{l}\text { RE } 397 \text { de } 12 \text { de } \\
\text { novembro de } 2004\end{array}$ & $\begin{array}{l}\text { Guia para provas de biodisponibilidade } \\
\text { relativa/bioequivalência }\end{array}$ & $\begin{array}{l}\text { RE } 1170 \text { de } 19 \text { de } \\
\text { abril de } 2006\end{array}$ & $\begin{array}{l}\text { http://www.interfarma.org.br/site2/ } \\
\text { images/Site\%20Interfarma/Informaco } \\
\text { esdosetor/RE/Registro/2006/ } \\
\text { RE\%201170-06\%20SIMILAR.pdf }\end{array}$ \\
\hline $\begin{array}{l}\text { RE } 1170 \text { de } 19 \text { de } \\
\text { abril de } 2006\end{array}$ & $\begin{array}{l}\text { Guia para provas de biodisponibilidade } \\
\text { relativa/bioequivalência de medicamentos }\end{array}$ & Em vigor & $\begin{array}{l}\text { http://www.interfarma.org.br/site2/ } \\
\text { images/Site\%20Interfarma/Informaco } \\
\text { esdosetor/RE/Registro/2006/ } \\
\text { RE\%201170-06\%20SIMILAR.pdf }\end{array}$ \\
\hline $\begin{array}{l}\text { RDC } 221 \text { de } 28 \text { de } \\
\text { dezembro de } 2006\end{array}$ & $\begin{array}{l}\text { Institui a Rede Brasileira de Centros Públicos de } \\
\text { Equivalência Farmacêutica e Bioequivalência }\end{array}$ & Em vigor & $\begin{array}{l}\text { http://www.anvisa.gov.br/ } \\
\text { legis/resol/2006/rdc/221_06.pdf }\end{array}$ \\
\hline $\begin{array}{l}\text { RDC } 17 \text { de } 2 \text { de } \\
\text { março de } 2007\end{array}$ & Regulamento técnico para medicamentos genéricos & Em vigor & $\begin{array}{l}\text { http://www.interfarma.org.br/site2/ } \\
\text { images/Site\%20Interfarma/Informaco } \\
\text { esdosetor/RE/Registro/2007/ } \\
\text { RDC\%2016-07.pdf }\end{array}$ \\
\hline
\end{tabular}

